\title{
Application of pearl millet in functional food
}

Priti G. Kale and Pravin R. Vairagar

Received : $10.04 .2018 ;$ Accepted : 13.04 .2018

See end of the Paper for authors' affiliation

Correspondence to :

Priti G. Kale

Department of Agricultural Engineering, Maharashtra Institute of Technology, Aurangabad (M.S.) India
- Abstract : Pearl millet (Pennisetum glaucum) is locally known as bajra. It is drought resistant crop and gives good productivity in areas with low rainfall, low soil fertility and high temperature where other cereal crops, such as wheat, rice and maize are not grown properly. Pearl millet is the staple food for economically poorer section of the world's population, due to all these characteristics of pearl millet it is considered as a poor man's cereals. Pearl millet is rich source of phytochemicals and micronutrients play important role in our immune system. Also pearl millet has antioxidant properties which help to reduce blood pressure, risk of heart disease, diabetes, prevention of cancer, cardiovascular diseases, etc. Other health benefits is high fibre which helps to dealing with constipation, high amount of iron and zinc specially biofortified varieties which help to overcome the problem of mineral deficiency. Pearl millet is gluten free and after being cooked it is the only grain which retains its alkaline properties. All these characteristics of pearl millet makes it good source of functional food. Aim of this paper is reviews the application of pearl millet in functional food.

- Key words : Pearl millet, Cereal, Functional food, Mineral, Biofortified, Deficiency

- How to cite this paper : Kale, Priti G. and Vairagar, Pravin R. (2018). Application of pearl millet in functional food. Internat. J. Agric. Engg., 11(Sp. Issue) : 90-94, DOI: 10.15740/HAS/IJAE/11.Sp. Issue/90-94. 